This document is confidential and is proprietary to the American Chemical Society and its authors. Do not copy or disclose without written permission. If you have received this item in error, notify the sender and delete all copies.

\title{
Electronic Transition of Ferrocenium: Neon Matrix and CASPT2 Studies
}

\begin{tabular}{|r|l|}
\hline Journal: & The Journal of Physical Chemistry \\
\hline Manuscript ID & jp-2016-10391t.R1 \\
\hline Manuscript Type: & Special Issue Article \\
\hline Date Submitted by the Author: & 26-Nov-2016 \\
\hline Complete List of Authors: & $\begin{array}{l}\text { Fulara, Jan; Polska Akademia Nauk, Institute of Physics; University of } \\
\text { Basel, Department of Chemistry } \\
\text { Filipkowski, Karol; University of Basel, physical chemistry } \\
\text { Maier, John; University of Basel, Department of Chemistry }\end{array}$ \\
\hline
\end{tabular}

\section{SCHOLARONE ${ }^{\text {ix }}$}

Manuscripts 


\title{
Electronic Transition of Ferrocenium: Neon Matrix and CASPT2 Studies
}

\author{
Jan Fulara, ${ }^{1,2}$ Karol Filipkowski, ${ }^{1}$ John P. Maier ${ }^{*}, 1$ \\ ${ }^{1}$ Department of Chemistry, University of Basel, Klingelbergstrasse 80, CH-4056, Basel, \\ Switzerland \\ ${ }^{2}$ Institute of Physics, Polish Academy of Sciences, Al. Lotników, 32/46, PL-02-668 Warsaw, \\ Poland
}

\begin{abstract}
Electronic absorptions of ferrocenium starting at $632.5 \mathrm{~nm}$ were measured in a $6 \mathrm{~K}$ neon matrix following mass - selective deposition of the ions. The spectrum shows clear vibrational structure and provides the best yet resolved view of the electronic states of this cation. The absorption system is identified as the $1{ }^{2} \mathrm{E}_{1}{ }^{\prime} \leftarrow \mathrm{X}^{2} \mathrm{E}_{2}{ }^{\prime}$ transition $\left(\mathrm{D}_{5 \mathrm{~h}}\right.$ symmmetry) on the basis of vertical excitation energies and oscillator strengths calculated at the CASPT2 level. Vibrational bands in the spectrum are assigned with the aid of the ground state frequencies calculated with the DFT method.
\end{abstract}




\section{Introduction}

Ferrocene, dicyclopentadienyl iron, $\left(\mathrm{FeCp}_{2}\right)$ was discovered in the middle of the last century ${ }^{1,2}$ and since then was a subject of numerous experimental and theoretical studies ${ }^{3}$. Ferrocene is a stable, non-toxic, readily functionalizing compound having, in addition, a low redox potential. Due to these unique features ferrocene - based materials are of interest in electrochemistry, biology, pharmacy and materials science. They can be used as catalysts ${ }^{4,5}$, biosensors ${ }^{6}$ or anticancer drugs ${ }^{7,8}$. Ferrocenium $\left(\mathrm{FeCp}_{2}{ }^{+}\right)$plays a key role in these systems, for example it is responsible for the cytotoxic activity against cancer cells ${ }^{9,10}$.

In contrast to neutral ferrocene, much less is known about its ion, although the first electronic absorption spectrum of ferrocenium was already measured in the late fifties as a charge transfer complex with iodine ${ }^{11}$. Several spectroscopic studies on $\mathrm{FeCp}_{2}{ }^{+}$in strong Lewis acids and on ferrocenium salts in solid environment ${ }^{12-14}$ have been carried out and structured absorptions starting around $630 \mathrm{~nm}$ were reported. The ground state of $\mathrm{FeCp}_{2}{ }^{+}$was characterized as ${ }^{2} \mathrm{E}_{2 \mathrm{~g}}$ (in $\mathrm{D}_{5 \mathrm{~d}}$ symmetry) by electron spin resonance ${ }^{15,16}$, magnetic susceptibility ${ }^{14}$ and neutron scattering studies ${ }^{17}$. Theoretical studies ${ }^{18,19}$ on $\mathrm{FeCp}_{2}{ }^{+}$have revealed that the transition observed in the visible range is due to electronic excitation to the ${ }^{2} \mathrm{E}_{1 \mathrm{u}}$ state. The ${ }^{2} \mathrm{E}_{1 \mathrm{u}} \leftarrow \mathrm{X}^{2} \mathrm{E}_{2 \mathrm{~g}}$ transition was studied in the gas-phase by photodissociation spectroscopy; however the resolution was poor and vibrational structure was not observed ${ }^{20}$. Photoelectron studies on ferrocene give some insight on the energetics of the ground and several excited electronic states of its cation ${ }^{21,22}$.

In this contribution the electronic absorption spectrum of ferrocenium in solid neon is reported and assigned to the $1{ }^{2} \mathrm{E}_{1}{ }^{\prime} \leftarrow \mathrm{X}^{2} \mathrm{E}_{2}{ }^{\prime}$ transition $\left(\mathrm{D}_{5 \mathrm{~h}}\right)$ based on CASPT2 calculations. 


\section{Experimental}

The set-up used employs mass-selected ion deposition into a $6 \mathrm{~K}$ neon matrix. Ferrocenium ions were produced in a hot cathode discharge from a mixture of ferrocene vapours with helium at room temperature. Ions were extracted from the source by a series of electrodes and guided into an electrostatic bender, separating neutral and ionic species. After passing through a mass filter cations were co-deposited with neon onto a rhodium-coated sapphire plate to build $\sim 150 \mu \mathrm{m}$ matrix over 4-5 hours. Chloromethane mixed with neon in a 1:25000 ratio was used as an electron scavenger to prevent the neutralization of trapped ions by electrons ejected from metal surfaces.

Absorption spectra were recorded by probing the matrix with broadband light from a halogen or xenon lamp, parallel to the sapphire substrate in a waveguide manner. The light transmitted through the matrix was collected by an optic-fiber bundle. Collected light illuminated the slit of $0.3 \mathrm{~m}$ spectrograph combined with two wavelength-specific CCD cameras. The electronic absorption spectra in the $220-1100 \mathrm{~nm}$ range were obtained by recording a series of overlapping $50-70 \mathrm{~nm}$ sections and then merging them. The measurements were started in near IR and continued towards UV using appropriate cut-off filters, to avoid neutralization or photoconversion of trapped ions. Ions were then neutralized with UV photons $(\lambda>260 \mathrm{~nm})$ from a medium pressure mercury lamp, and the spectrum recorded anew to distinguish the absorption of neutrals and charged species. 


\section{Computational}

To assign the electronic spectrum of ferrocenium, the symmetry and excitation energy of the electronic states involved and oscillator strength were calculated by ab initio methods. A sufficiently large basis set for iron is needed. The Wachters $+\mathrm{f}$ basis set for iron ${ }^{23,24}$, aug-cc-pVDZ for carbon ${ }^{25}$ and hydrogen and the B3LYP functional ${ }^{26}$ were used for geometry optimization. Calculations have been done with the Gaussian 09 program package ${ }^{27}$. Computations at the same level for the ferrocene itself provided almost the same frequencies of the vibrational modes as in ref. 28 (Table 1SI). Two arrangements of the $C p$ rings: eclipsed $\left(D_{5 \mathrm{~h}}\right)$ and staggered $\left(D_{5 \mathrm{~d}}\right)$ can be distinguished, separated by a low energy barrier $(\sim 4 \mathrm{~kJ} / \mathrm{mol} \text { for the neutral })^{28}$. A minimum for ferrocinium is predicted at $D_{5 \mathrm{~h}}$ symmetry. One imaginary frequency $(-36 \mathrm{~cm}-1)$ and a slightly higher energy $(\sim 1 \mathrm{~kJ} / \mathrm{mol})$ is obtained for the $\mathrm{D}_{5 \mathrm{~d}}$ structure (Table $\left.2 \mathrm{SI}\right)$. The coordinates of the ground electronic state computed at the DFT level of theory were used for the excitation energy and oscillator strength predictions of the $\mathrm{D}_{5 \mathrm{~h}}$ and the $\mathrm{D}_{5 \mathrm{~d}}$ transition state structure. For computational reasons, these were carried out using the ANO L/5s4p2d1f, ANO L/3s2p1d and ANO L/2s1p basis set for iron, carbon and hydrogen atoms, respectively and the symmetries were lowered to the $C_{2 v}$ and $C_{2 h}$ point groups. Multi-state second-order perturbation theory ${ }^{29,30}$ was employed, and the wavefunctions were optimized for the average energy of the four roots. Molcas 8 program ${ }^{31}$ was used. Eleven electrons residing on the HOMO orbitals, which belong to $a_{1}, b_{1}, a_{2}$ and $b_{2}$ irreducible representations of $C_{2 v}$ (the largest abelian subgroup of $D_{5 h}$ ), were distributed on twelve orbitals and formed the active space in the multistate CASPT2 calculations. The orbitals and the active space are shown schematically in Fig. 1SI. The ground electronic state of ferrocenium belongs to the $E_{2}^{\prime}$ irreducible representation of $\mathrm{D}_{5 \mathrm{~h}}$ and the first excited state to the $E_{2}^{\prime}$. At the lower $\mathrm{C}_{2 \mathrm{~V}}$ symmetry both electronic states belong to the $\mathrm{a}_{1}+\mathrm{b}_{1}$ representations. The 
energy of $\mathrm{X}{ }^{2} E_{2}^{\prime}$ and $1^{2} E_{1}^{\prime}$ states is equal to the $\mathrm{a}_{1}$ and $\mathrm{b}_{1}$ representations. The same is observed for the excitation energies and the oscillator strengths (see Supporting Information for a more extended discussion).

\section{Results and Discussion}

Deposition of ferrocene cations into solid neon resulted in strong absorptions commencing at $632.5 \mathrm{~nm}$ (blue trace, Figure 1). The absorptions diminished upon UV irradiation $(\lambda>260 \mathrm{~nm})$ of the matrix (red trace), suggesting cationic carrier. The origin band and the next strongest one at $621.0 \mathrm{~nm}$ show a triplet structure, with spacing of 25 and $63 \mathrm{~cm}^{-1}$. The same motif, although less pronounced, is seen for the other vibrational bands. The wavelength of the origin band in solid neon $(632.5 \mathrm{~nm})$ lies not far from that one reported in solution $(\sim 635 \mathrm{~nm})^{13,14}$ or $\mathrm{KBr}$ pellet ( around $640 \mathrm{~nm})^{12}$. The separation of the first two bands in the photoelectron spectrum of ferrocene $\mathrm{e}^{21}$ (with a typical uncertainty of $\pm 80 \mathrm{~cm}^{-1}$ ) yields the wavelengths of $674 \pm 4$ $\mathrm{nm}$ for the vertical energy to the first excited electronic state and $621.5 \pm 3 \mathrm{~nm}$ for the adiabatic one $^{22}$. Vibrational structure with a spacing of $\sim 278 \pm 80 \mathrm{~cm}^{-1}$ is apparent in the photoelectron spectrum of ferrocene ${ }^{22}$. The progression built on the same vibrational mode, $293 \mathrm{~cm}^{-1}$, dominates the neon matrix absorption spectrum (Figure 1). The gas-phase photoelectron data to neon matrix shift of the origin band is, in the range observed for a large number of cations ${ }^{32-34}$.

The strongest $1{ }^{2} \mathrm{E}_{1 \mathrm{u}} \leftarrow \mathrm{X}^{2} \mathrm{E}_{2 \mathrm{~g}}$ electronic transition of the $\mathrm{D}_{5 \mathrm{~d}}$ structure is predicted at 2.04 $\mathrm{eV}$ with an oscillator strength (f) of 0.007 and the $1{ }^{2} \mathrm{E}_{1}{ }^{\prime} \leftarrow \mathrm{X}^{2} \mathrm{E}_{2}{ }^{\prime}$ transition of the $\mathrm{D}_{5 \mathrm{~h}}$ structure at $2.44 \mathrm{eV}(\mathrm{f}=0.012)$. These can be compared with the onset at $632.5 \mathrm{~nm}(1.96 \mathrm{eV})$ in solid neon. The vertical excitation energy computed with the same basis set and a smaller active space (11 electrons distributed on 11 orbitals) is slightly larger $(2.52 \mathrm{eV})$ and the respective adiabatic value 
obtained is $2.31 \mathrm{eV}$. The latter computed with a larger basis set should match better the observation.

Ionization of ferrocene $\left(\mathrm{D}_{5 \mathrm{~h}}\right)$ was studied by the symmetry adapted cluster-configurationinteraction method and energies of several excited electronic states of $\mathrm{FeCp}_{2}{ }^{+}$were reported ${ }^{35}$. The ground state of the cation has ${ }^{2} \mathrm{E}_{2}$ symmetry and the first electronic transition to the $1{ }^{2} \mathrm{E}_{1}{ }^{\prime}$ state is expected in the optical domain at $2.52 \mathrm{eV}$, close to the CASPT2 energy. The next electronic state of the same symmetry lies at $6.37 \mathrm{eV}$. The bonding nature of the ground and excited electronic states of $\mathrm{FeCp}_{2}{ }^{+}$has also been discussed ${ }^{35}$. Ferrocene is an example where Koopmans' theorem breaks down; the ground state of $\mathrm{FeCp}_{2}{ }^{+}$is formed upon removal of an electron from the inner $\mathrm{e}_{2}$ ' orbital, mainly composed of the $3 \mathrm{~d}_{\mathrm{xy}}$ and $3 \mathrm{~d}_{\mathrm{x} 2-\mathrm{y} 2}$ atomic orbitals of iron. The $1{ }^{2} \mathrm{E}_{1}$ ' state is produced upon removal of an electron from the $\mathrm{e}_{1}$ ' orbital, essentially the $\pi$ orbitals of $\mathrm{Cp}$ and $4 \mathrm{p}$ of iron $^{35}$. The present CASPT2 studies lead to the similar conclusions.

Based on the theoretical calculations, the electronic spectrum shown in Figure 1 is assigned to the $1^{2} \mathrm{E}_{1}{ }^{\prime} \leftarrow \mathrm{X}^{2} \mathrm{E}_{2}^{\prime}$ electronic transition of ferrocenium $\left(\mathrm{D}_{5 \mathrm{~h}}\right)$. The four strongest bands in the spectrum belong to a vibrational progression with spacings $\sim 290 \mathrm{~cm}^{-1}$ (Table 1). A similar vibrational structure was observed in frozen Lewis acids ${ }^{12}, \mathrm{KBr}$ pellets ${ }^{14}$ and the photoelectron spectrum of ferrocene $\mathrm{e}^{22}$. The $290 \mathrm{~cm}^{-1}$ frequency inferred is close to $292 \mathrm{~cm}^{-1}$, the value calculated at the DFT level for the $v_{4}$ vibration $\left(a_{1}{ }^{\prime}\right)$ in the ground state of the cation (Table 2SI and Fig. 2SI). $v_{4}$ is the totally symmetric ring - metal stretch and its energy does not differ much from the $303 \mathrm{~cm}^{-1}$ value observed in the Raman spectrum of the neutral ferrocene ${ }^{36}$. The $v_{4}$ fundamental forms combination bands with other vibrations (Fig. 1). Two other $\mathrm{a}_{1}$ ' vibrations $\left(v_{3}\right.$ and $v_{2}$ ) and their combinations with $v_{4}$ are identified in the spectrum. The remaining bands may result from the excitation of double quanta of non-totally symmetric vibrations and their combinations with $v_{4}$ or the other modes. One example of such an excitation is a weak band lying 
$216 \mathrm{~cm}^{-1}$ above the origin. There is no such mode in the calculated frequencies of either ferrocene or its cation (Tables SI1,2). The band appears as a double excitation of $v_{16}\left(\mathrm{e}_{1}{ }^{\prime}\right)$ with energy 112 $\mathrm{cm}^{-1}$. Combinations of $2 v_{16}$ with $v_{4}$ are responsible for the bands lying 501 and $785 \mathrm{~cm}^{-1}$ above the onset.

A number of possible combinations of different modes increases in short-wavelength part of the spectrum and assignment given in Table 1 is tentative. The $\operatorname{ESR}^{15,16}$ and neutron scattering ${ }^{17}$ studies show that the degenerate ground state of ferrocenium splits into two components around $515 \mathrm{~cm}^{-1}$ apart due to spin - orbit coupling and a Jahn -Teller distortion. ${ }^{37}$ The $1{ }^{2} \mathrm{E}_{1}$ ' electronic state also separates into a doublet and transitions to the two components are observed in the magnetic circular dichroism ${ }^{18}\left(500 \mathrm{~cm}^{-1}\right)$ and gas - phase photodissociation ${ }^{20}$ $\left(\sim 600 \mathrm{~cm}^{-1}\right)$ spectra of ferrocene cation.. However the resolution in the latter case was very low. Thus the band lying $501 \mathrm{~cm}^{-1}$ above the origin in absorption spectrum of ferrocene cation in neon could be the origin to the second doublet of the $1{ }^{2} \mathrm{E}_{1}$ ' state. At $6 \mathrm{~K}$ only electronic transitions from the lowest energy component of the $X^{2} E_{2}$ doublet are observed. Some weak bands above $613.1 \mathrm{~nm}$ may belong to the electronic transition of the second doublet component of the $1{ }^{2} \mathrm{E}_{1}^{\prime}$ state.

\section{Conclusions}

The present study provides the best vibrationally resolved electronic absorption spectrum of ferrocenium to date. It was obtained in a $6 \mathrm{~K}$ neon matrix following deposition of mass selected ions. The absorptions starting at $632.5 \mathrm{~nm}$ are assigned to the $1^{2} \mathrm{E}_{1}{ }^{\prime} \leftarrow \mathrm{X}^{2} \mathrm{E}_{2}{ }^{\prime}$ electronic transition on the basis of CASPT2 calculations. The strongest bands in the spectrum are due to 
vibrational excitations involving the $v_{4}$ - ring to metal stretching mode. The neon matrix spectrum provides the basis for gas-phase measurements of this cation in the future.

\section{Author Information \\ *E-mail: j.p.maier@unibas.ch. Phone: +41 (0)61 2673826. \\ Acknowledgement}

This work was supported by the Swiss National Science Foundation.

\section{Supporting Information Description}

- Extended discussion on the CASPT2 calculations

- Most significant configurations of ferrocenium, predicted by Molcas 8 program.

- $\quad$ Figure showing HOMO-LUMO orbitals of ferrocenium cation $\left(\mathrm{D}_{5 \mathrm{~h}}\right)$

- $\quad$ Figure of $\mathrm{v}_{4}$ normal mode

- Comparison of ground state vibrational frequencies of neutral ferrocene $\left(D_{5 h}\right)$ calculated with the DFT method and reference values from ref. 28 .

- Comparison of ground state vibrational frequencies of neutral $D_{5 h}$ and $D_{5 d}$ ferrocene cation calculated with the DFT method. 


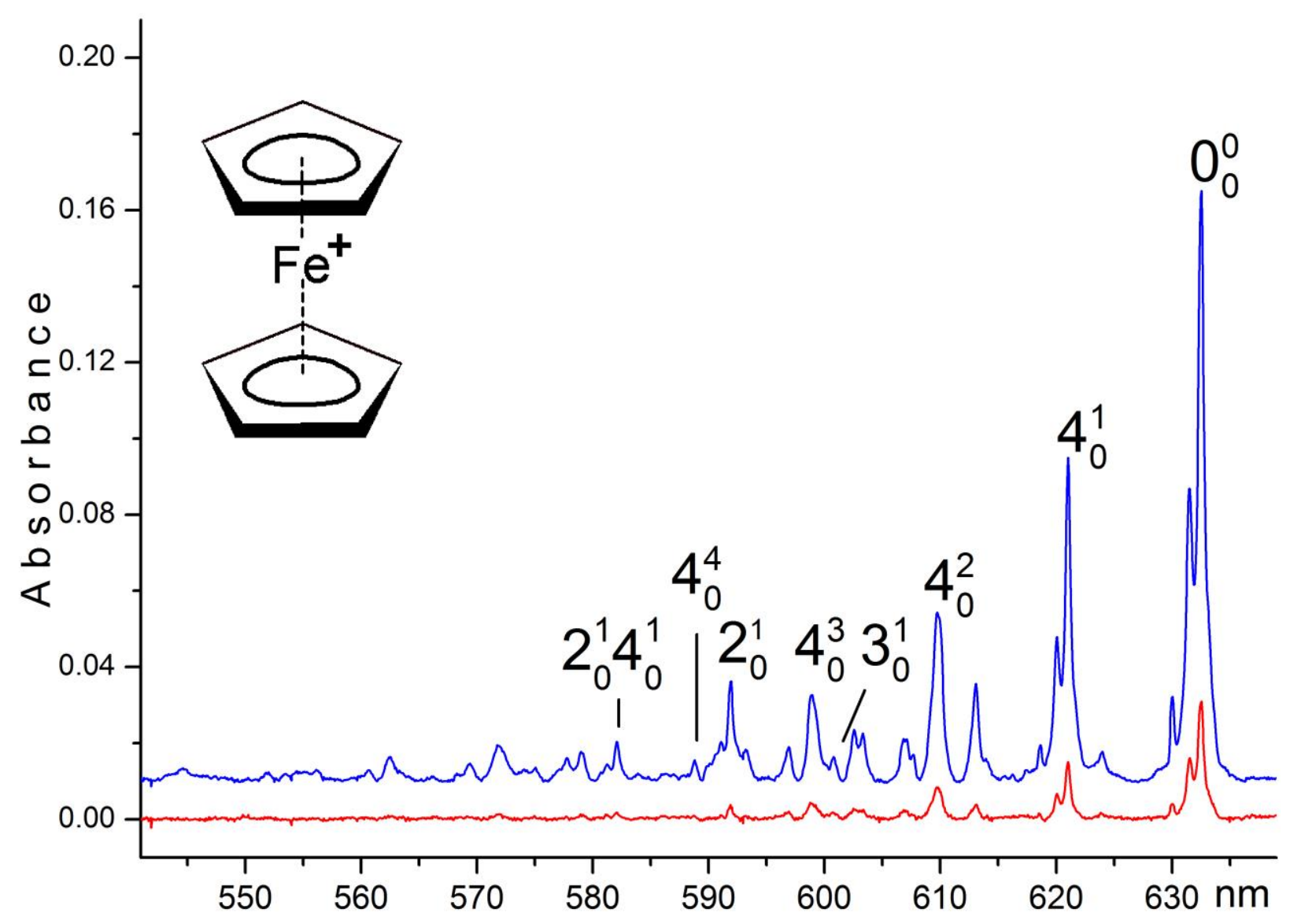

Figure $11^{2} E_{1}^{\prime} \leftarrow X^{2} E_{2}^{\prime}$ electronic absorption spectrum of ferrocenium ion $\left(D_{5 h}\right)$ in a $6 \mathrm{~K}$ neon matrix containing a trace of $\mathrm{CH}_{3} \mathrm{Cl}$, together with proposed assignments (blue trace). The red trace was recorded after irradiation with $\lambda>260 \mathrm{~nm}$ photons. 
Table 1. Observed band maxima $( \pm 0.1 \mathrm{~nm})$ in the absorption spectrum of ferrocenium $\left(\mathrm{D}_{5 \mathrm{~h}}\right.$ symmetry) in a $6 \mathrm{~K}$ neon matrix. The assignment is based on electronic excitation energy computed with the CASPT2 method and vibrational frequencies calculated for the ground electronic state, with DFT (Table 2SI).

\begin{tabular}{llll}
\hline$\lambda / \mathrm{nm}$ & $\tilde{v} / \mathrm{cm}^{-1}$ & $\Delta / \mathrm{cm}^{-1}$ & Assignment \\
\hline 632.5 & 15810 & 0 & $0_{0}^{0} 1^{2} \mathrm{E}_{1}{ }^{\prime} \leftarrow \mathrm{X}^{2} \mathrm{E}_{2}^{\prime}$ \\
624.0 & 16026 & 216 & $2 v_{16}$ \\
621.0 & 16103 & 293 & $v_{4}$ \\
613.1 & 16311 & 501 & $v_{4}+2 v_{16} \quad$ or ${ }^{\text {a) }} 0_{0}^{0}$ \\
609.7 & 16402 & 592 & $2 v_{4}$ \\
606.8 & 16480 & 670 & $2 v_{22}$ \\
603.3 & 16576 & 766 & $2 v_{15}$ \\
602.6 & 16595 & 785 & $2 v_{4}+2 v_{16}$ \\
600.8 & 16644 & 834 & $v_{3}$ \\
598.9 & 16697 & 887 & $3 v_{4}$ \\
596.9 & 16753 & 943 & \\
593.2 & 16858 & 1048 & $2 v_{15}+v_{4}$ \\
591.9 & 16895 & 1085 & $v_{2}$ \\
588.8 & 16984 & 1174 & $4 v_{4}$ \\
582.1 & 17179 & 1369 & $v_{2}+v_{4}$ \\
579.1 & 17268 & 1458 & \\
577.7 & 17310 & 1500 & $4 v_{15}$ \\
571.8 & 17489 & 1679 & \\
569.4 & 17562 & 1752 & $1458+v_{4}$ \\
562.4 & 17781 & 1971 & $1679+v_{4}$ \\
560.7 & 17835 & 2025 & \\
544.6 & 18362 & 2552 & \\
\hline a) The origin $0 f$ the electronic transition to the second Jahn-Teller component of the $1{ }^{2} \mathrm{E}_{1}{ }^{\prime}$ state.
\end{tabular}




\section{References}

${ }^{1}$ Kealy, T. J.; Pauson, P. L. A New Type of Organo-Iron Compound. Nature. 1951, 168, 1039-1040.

${ }^{2}$ Millers, S.A.; Tebboth, J.A.; Tremaine, J. F. Dicyclopentadienyliron . J. Chem. Soc. 1952, 632-635.

3 Adams, R.D. (2001) Special Issue: 50th Anniversary of the Discovery of Ferrocene. $J$. Organomet. Chem. 2001, 637-639.

${ }^{4}$ Atkinson, R. C. J.; Gibson V. C.; Long, N. J. The Syntheses and Catalytic Applications of Unsymmetrical Ferrocene Ligands. Chem. Soc. Rev. 2004, 33, 313-328.

${ }^{5}$ Shafir, A.; Arnold, J. Ferrocene-Based Olefin Polymerization Catalysts: Activation, Structure, and Intermediates. Organometallics, 2003, 22, 567-575.

${ }^{6}$ Sun, R.; Wang, L.; Yu, H.; Abdin, Z.-ul; Chen, Y.; Huang, J.; Tong, R. Molecular Recognition and Sensing Based on Ferrocene Derivatives and Ferrocene-Based Polymers. Organometallics 2014, 33, 4560-4573.

${ }^{7}$ Braga, S. S.; Silva, A. M. S. A New Age for Iron: Antitumoral Ferrocenes. Organometallics 2013, 32, 5626-5639.

${ }^{8}$ Fouda, M. F. R.; Abd-Elzaher, M. M.; Abdelsamaia, R. A.; Labib, A. A. On the Medicinal Chemistry of Ferrocene. Appl. Organometal. Chem. 2007, 21, 613-625.

9 Köpf-Maier, P.; Köpf, H.; Neuse, E. W. Ferrocenium Salts-the First Antineoplastic Iron Compounds. Angew. Chem., Int. Ed. Engl. 1984, 23, 456-457.

${ }^{10}$ Houlton, A.; Roberts, R.M.G.; Silver, J. Studies on the Anti-Tumour Activity of Some Iron Sandwich Compounds. J. Organomet. Chem. 1991, 418, 107-112.

${ }^{11}$ Brand, J. C. D.; Snedden, W.; Electron-Transfer Spectra of Ferrocene. Trans. Faraday Soc. 1957, 53, 894-900. 


\begin{abstract}
${ }^{12}$ Sohn, Y. S.; Hendrickson, D. N.; Gray, H. B. Electronic Structure of Ferricenium Ion. J. Am. Chem. Soc. 1970, 92, 3233-3234.

13 Sohn, Y. S.; Hendrickson, D. N.; Gray, H. B. Electronic Structure of Metallocenes J. Am. Chem. Soc. 1971, 93, 3603-3612.
\end{abstract}

${ }^{14}$ Hendrickson, D. N.; Sohn, Y. S.; Duggan D. M.; Harry, B. G. Low-Temperature $\left(4.2^{\circ}\right.$ K) Study of the ${ }^{2} \mathrm{E}_{1 \mathrm{u}} \leftarrow{ }^{2} \mathrm{E}_{2 \mathrm{~g}}$ Band System in the Electronic Spectra of Various Ferricienium Compounds. J. Chem. Phys. 1973, 58, 4666-4675.

15 Prins, R.; Reinders, F. J. Electron Spin Resonance of the Cation of Ferrocene J. Am. Chem. Soc. 1969, 91, 4929-4931.

16 Prins, R. Electronic Structure of the Ferricenium Cation; Electron Spin Resonance Measurements of the Cations of Ferrocene Derivatives. Mol. Phys. 1970, 19, 603-620.

${ }^{17}$ Kemner, E.; de Schepper, I. M.; Kearley, G. J. The Vibrational Spectrum of Solid Ferrocene by Inelastic Neutron Scattering. J. Chem. Phys. 2000, 112, 10926-10929.

${ }^{18}$ Rowe, M. D.; McCaffery, A. J. Electronic Structure of Ferricenium Ion from Absorption, MCD, and ESR Studies. J. Chem. Phys. 1973, 59, 3786-3794

${ }^{19}$ Bagus, P. S.; Walgren U. I.; Almlof J. A Theoretical Study of the Electronic Structure of Ferrocene and Ferricinium: Application to Mössbauer Isomer Shifts, Ionization Potentials, and Conformation. J. Chem. Phys. 1976, 64, 2324-2334.

${ }^{20}$ Faulk, J. D.; Dunbar R. C. Photodissociation Spectroscopy of Gas-Phase Ferrocene Cation. J. Am. Soc. Mass. Spectrom.1991, 2, 97-102.

${ }^{21}$ Evans, S.; Green, M. L. H.; Jewitt, B.; King, G. H.;Orchard, A. F. Electronic Structures of Metal Complexes Containing the $\pi$-Cyclopentadienyl and Related Ligands. Part 2.- He I Photoelectron Spectra of the Open-Shell Metallocenes. J. Chem. Soc. Faraday II 1974, 70, 356-376. 


\footnotetext{
${ }^{22}$ Rabalais, J. W.; Werme, L. O.; Bergmark, T.; Karlsson, L.; Hussain, M.; Siegbahn K. Electron Spectroscopy of Open - Shell Systems: Spectra of $\mathrm{Ni}\left(\mathrm{C}_{5} \mathrm{H}_{5}\right)_{2}, \quad \mathrm{Fe}\left(\mathrm{C}_{5} \mathrm{H}_{5}\right)_{2}, \mathrm{Mn}\left(\mathrm{C}_{5} \mathrm{H}_{5}\right)_{2}$, and $\mathrm{Cr}\left(\mathrm{C}_{5} \mathrm{H}_{5}\right)_{2}$. J. Chem. Phys. 1972, 57, 1185-1192.

${ }^{23}$ Feller, D. The Role of Databases in Support of Computational Chemistry Calculations. J. Comp. Chem. 1996, 17, 1571-1586.
}

${ }^{24}$ Schuchardt, K. L.; Didier, B. T.; Elsethagen, T.; Sun, L.; Gurumoorthi, V.; Chase, J.; Li, J.; Windus, T.L. Basis Set Exchange: A Community Database for Computational Sciences. J. Chem. Inf. Model. 2007, 47, 1045-1052.

${ }^{25}$ Dunning, T. H. Jr. Gaussian Basis Sets for use in Correlated Molecular Calculations. I. The Atoms Boron through Neon and Hydrogen. J. Chem. Phys. 1989, 90, 1007-1023.

${ }^{26}$ Lee, C.; Yang, W.; Parr, R. G.; Development of the Colle-Salvetti Correlation-Energy Formula into a Functional of the Electron Density. Phys. Rev. 1988, B 37, 785-789.

${ }^{27}$ Gaussian 09, Revision D.01, Frisch, M. J.; Trucks, G. W.; Schlegel, H. B.; Scuseria, G. E.;

Robb, M. A.; Cheeseman, J. R.; Scalmani, G.; Barone, V.; Mennucci, B.; Petersson, G.; et. al. Gaussian, Inc., Wallingford CT, 2009.

${ }^{28}$ Xu, Z.- F.; Xie, Y.; Feng, W.-L.; Schaefer, H. F. III. Systematic Investigation of Electronic and Molecular Structures for the First Transition Metal Series Metallocenes $\mathrm{M}\left(\mathrm{C}_{5} \mathrm{H}_{5}\right)_{2}(\mathrm{M}=\mathrm{V}, \mathrm{Cr}$, Mn, Fe, Co, and Ni). Phys. Chem. A 2003, 107, 2716-2729.

${ }^{29}$ Andersson, K.; Malmqvist, P.-Å.; Roos, B. O.; Sadlej, A. J.; Wolinski, K. Second-Order Perturbation Theory with a CASSCF Reference Function. J. Phys. Chem. 1990, 94, 5483-5488.

${ }^{30}$ Andersson, K.; Malmqvist, P.-Å.; Roos, B. O. Second-Order Perturbation Theory with a Complete Active Space Self-Consistent Field Reference Function. J. Chem. Phys. 1992, 96, 1218-1226.

${ }^{31}$ Aquilante, F.; De Vico, L.; Ferré, N.; Ghigo, G.; Malmqvist, P.-Å; Neogrády, P.; Pedersen, T.B.; Pitonak, M.; Reiher, M.; Roos, B.O. et al. Comp. Chem. 2010, 31, 224-247. 
${ }^{32}$ Campos, F. X.; Jiang, Y.; Grant, E. R. Triple-Resonance Spectroscopy of the Higher Excited States of $\mathrm{NO}_{2}$. II. Vibrational Mode Selectivity in the Competition Between Predissociation and Autoionization. J. Chem. Phys. 1990, 93, 7731-7739

${ }^{33}$ Weaver, A.; Arnold, D. W.; Bradforth, S. E. Examination of the ${ }^{2} A_{2}^{\prime}$ and ${ }^{2} E^{\prime}$ States of $\mathrm{NO}_{3}$ by Ultraviolet Photoelectron Spectroscopy of $\mathrm{NO}_{3}^{-}$. J.Chem. Phys. 1991, 94, 1740-1751.

${ }^{34}$ Warren, D. F.; Thompson, W. E.; Jacox, M. E. The Vibrational Spectra of Molecular Ions Isolated in Solid Neon. XI. $\mathrm{NO}_{2}^{+}, \mathrm{NO}_{2}^{-}$, and $\mathrm{NO}_{3}^{-}$. J. Chem.Phys. 1993, 99, 7393-7402

${ }^{35}$ Ishimura, K.; M. Hada, M.; Nakatsuji, H. Ionized and Excited States of Ferrocene: Symmetry Adapted Cluster-Configuration-Interaction Study. J. Chem. Phys. 2002, 117, 6533-6537.

${ }^{36}$ Lippincott, E. R.; Nelson, R. D. The Vibrational Spectra and Structure of Ferrocene and Ruthenocene. Spectrochim. Acta, 1958, 10, 307-329.

${ }^{37}$ Stebler, A.; Furrer, A.; Ammeter, J. H. Direct Observation of the Ground-State Splitting in $\mathrm{d}^{5}$ and $\mathrm{d}^{7}$ Metallocenes by Inelastic Neutron Scattering. Inorg. Chem. 1984, 23, 3493-3500. 


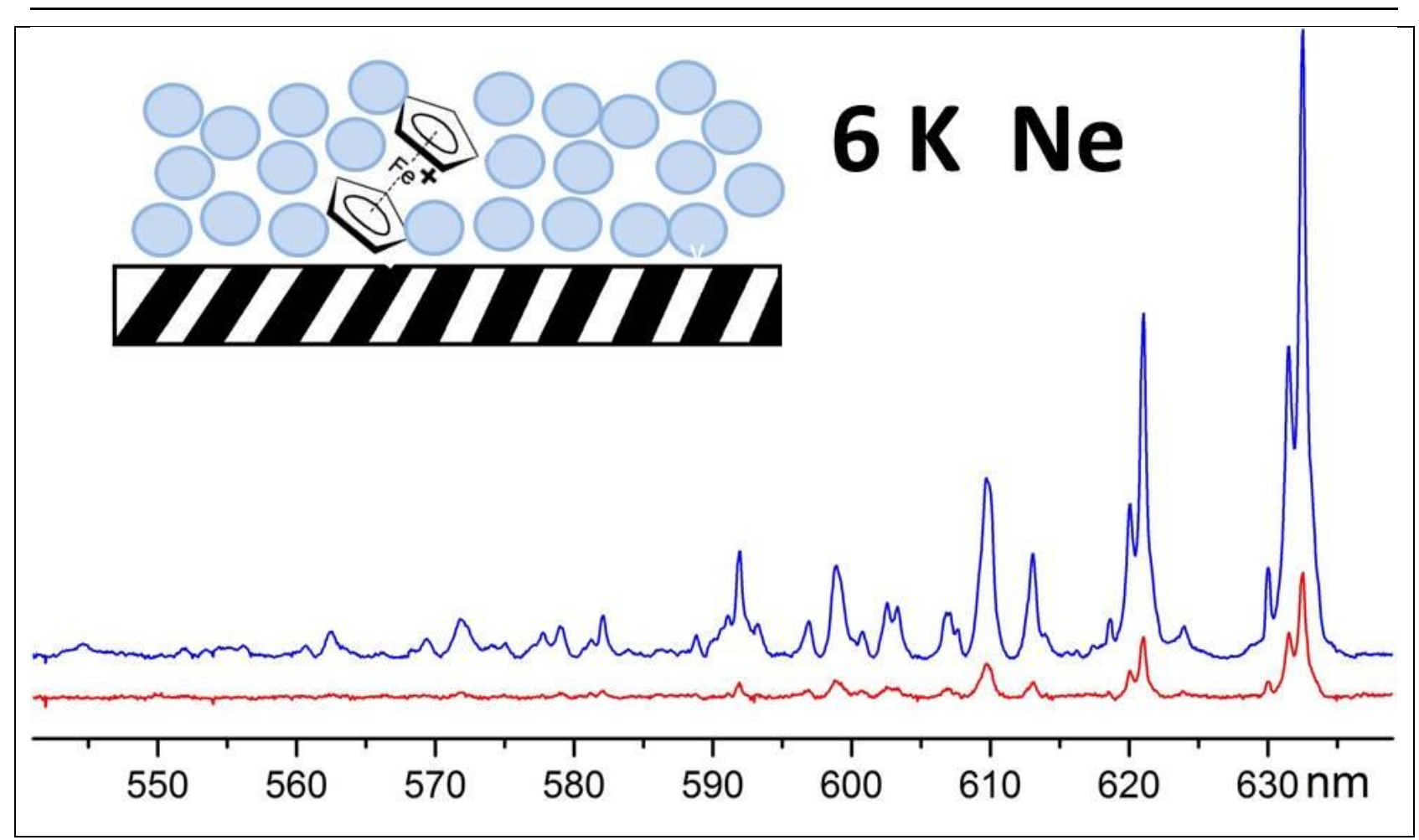

Table of Contents Graphic 


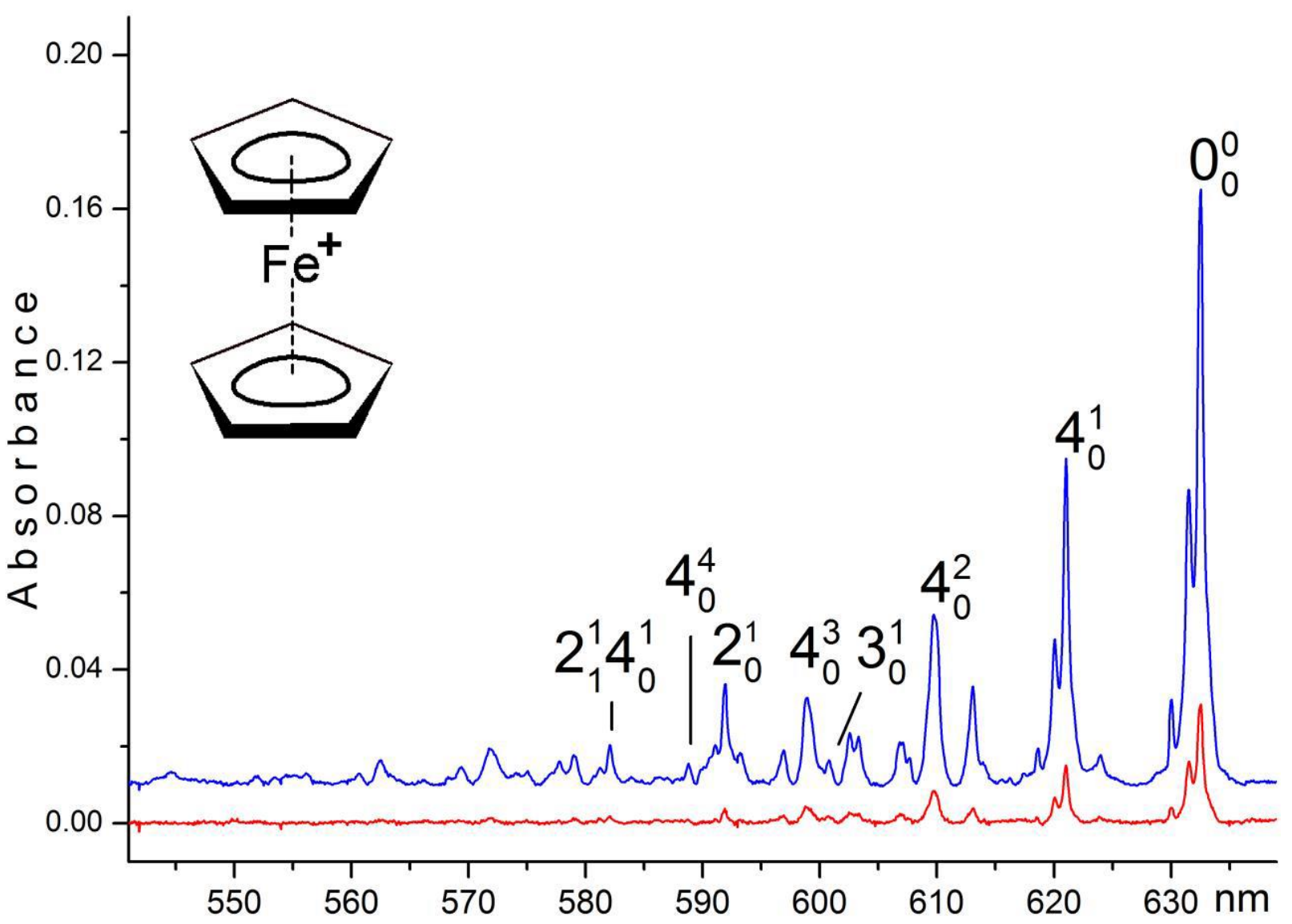

Figure $11^{2} E_{1}^{\prime} \leftarrow X^{2} E_{2}^{\prime}$ electronic absorption spectrum of ferrocenium ion $\left(D_{5 h}\right)$ in a $6 \mathrm{~K}$ neon matrix containing a trace of $\mathrm{CH}_{3} \mathrm{Cl}$, together with proposed assignments (blue trace). The red trace was recorded after irradiation with $\lambda>260 \mathrm{~nm}$ photons. 